\title{
The Effect of Packaging Size on Purchase Intention: The Case of Tunisian Olive Oil in the USA Market
}

\author{
Imene Trabelsi Trigui, Mohamed Abdelmoula \\ Email address: \\ imentrigui@yahoo.fr.com (I. T. Trigui),mohamed.abdelmoulaa@gmail (M. Abdelmoula)
}

Department of Management, Marketing Research Laboratory, Faculty of Economics and Management Science, Sfax University, Sfax, Tunisia

\section{To cite this article:}

Imene Trabelsi Trigui, Mohamed Abdelmoula. The Effect of Packaging Size on Purchase Intention: The Case of Tunisian Olive Oil in the USA Market. International Journal of Business and Economics Research. Vol. 8 No. 5, 2019, pp. 320-324. doi: 10.11648/j.ijber.20190805.19

Received: July 17, 2019; Accepted: August 19, 2019; Published: August 29, 2019

\begin{abstract}
In response to today's needs and changes in the international market in which many products travel all around the world, this study investigates the impact of packaging size upon perceived value for money and purchase intentions. Although existing literature has provided ample evidence that packaging size is able to influence consumers' behaviour and decision-making, still scarce research has explored what the size should be to succeed in exporting to new markets and attract more consumers, so it can possibly enhance perceptions value for money and lead to higher purchase intentions. This research examines how packaging size can influence purchase intention when this relation is mediated by value for money and identifies the optimal packaging size for olive oil bottles in the USA market. Experimentation was the selected methodology for our study and two online surveys were conducted for data collection. Our findings reveal that consumers prefer small packaging of olive oil bottles. This research provides important implications for managers who will improve their sales by taking into account the value for money approach and adapt Olive Oil packaging size to the specificities and preferences of the target market.
\end{abstract}

Keywords: Olive Oil, Packaging Size, Purchase Intention, Consumer Preferences, Value for Money

\section{Introduction}

Packaging is a relevant tool in marketing and a very important parameter for buyers and it is especially important in creating competitive advantages. Apart of his standard function of protecting the content, it conveys product quality and it can be the main reason for a brand's existence because it communicates brand identity, attracts attention in commercial contexts and positions the product within a concrete category [5]. The literature reveals several elements of packaging design), for example size, colour, labels and shape which emerge as crucial elements [12]. Co-creation through digital platforms have also recently contributed to take into account consumer preferences regarding his co-designed packaging expectations [2].

Nowadays, the demand by consumers for value added food products has remarkably increased instead of for greater quantities of food [7], and the unequal consumption between regions in the world, which seems to be high in the industrialised countries than in developing countries [14].

Moreover, the new life styles, the smaller households in some regions and the increased consciousness of consumers searching for convenience and smarter packaging guaranteeing traceability, make the adaptation of the packaging size to these specific consumer needs a necessity for a company, to gain a defendable and substantial competitive advantage in the foreign markets [8]. Thus, in order to enter a new big and interesting market as USA, it is very important to understand the preferences and the behaviour of US consumers regarding the olive oil. As mentioned, packaging is very important and behaviours of consumers around the world are different and moving everyday because of the new lifestyles and the increased health concerns [1]. Therefore, determining the optimal size of olive oil bottles needed and preferred by this community, is very crucial to have a suitable and successful positioning into the retail shelves. This issue has been widely ignored in previous research.

Our research paper investigates the topic of the packaging size through an interesting relationship between packaging size and purchase intention, while this relation is mediated by value for money. For this purpose, we conducted two different 
studies and we intended to answer the following main research questions:

Does packaging size affect the purchase intention? Is this relation mediated by value for money?

\section{Theoretical Background}

Nowadays, reaching new markets, attracting new customers, retaining existing customers and gaining a competitive advantage are the main concerns of many companies. Due to severe competitive pressure, and to satisfy consumers' needs, companies implement different strategies and practices of marketing to persuade customers or even compel them to purchase their products among various brands. According to their activities, companies use high quality, cute and well-designed and stylish packaging [15]. According to previous studies dealing with consumers behaviour towards packaging at the moment of purchase, different determinants were mentioned by authors such as packaging design, shape, and colour. However, the size of the packaging is another feature that affects sales [10]. In fact, in a study conducted by Delgado et al (2013) [3], they found that the size of olive oil package is ranked as the second most important factor which influences the purchase of olive oil in America after the extra virgin olive oil category.

When talking about size and consumer satisfaction, perceived value comes. This latter is defined as customers' assessment of costs and benefits of purchasing a product or service. The results of previous researches suggest that perceived value increases customers' satisfaction, and further purchase intention. Perceived value is a factor coming after perceived quality and considered as a pre-condition variable for value. Zeithaml (1988) [17] has suggested that perceived value can be regarded as a consumer's overall assessment of the utility of a product (or service) based on perceptions of what is received and what is given. This assessment is a kind of comparison of a product or service's "get" and "give" components.

Consumer intention to purchase depends on the degree to which consumers expect that the product can satisfy their expectations about its use [9]. Therefore, package becomes a critical factor in the consumer decision-making process because it communicates to consumers different extrinsic and intrinsic cues. Intention to purchase depends on the degree to which consumers expect the product to satisfy their needs when they consume it [9]. Two main packaging elements potentially affect consumer purchase decisions: visual and informational elements. The visual elements consist of graphics and size/shape of packaging, and relate more to the affective side of decision-making and the informational elements relate to information provided and technologies used in the package, and are more likely to address the cognitive side of decisions [16].

In this study, thanks to Faceoil project ${ }^{1}$, we decided to

\footnotetext{
${ }^{1}$ Faceoil Project: The Fund for Academic Cooperation and Exchange between Denmark and Arab Countries has conducted a research project involving Aarhus
}

investigate the effect of packaging size on purchase intention when this relation could be mediated by the value for money.

Thus, we propose the following research model:

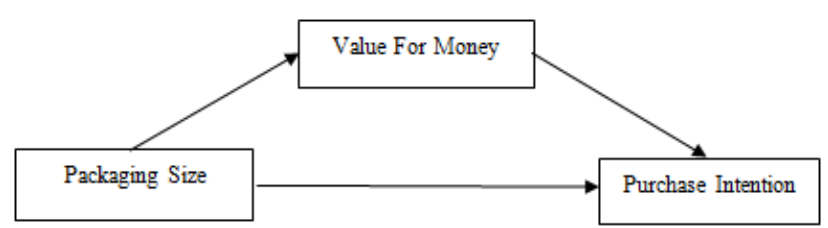

Figure 1. Proposed Research Model.

In our knowledge, our study is the first one to investigate this effect when it's mediated by value for money through two different studies when the unit price is the same for the three sizes and when unit price changes.

Through previous studies it is very important to consider packaging size as a very important factor which influences purchase intention, and it should receive the necessary attention. In our case as we are focusing on olive oil packaging, we suggest the following hypotheses:

H1: Olive oil packaging size affects consumer purchase intention

H2: Value for money mediates the relationship between Packaging size and purchase intention.

\section{Research Method}

To answer the overall research question, two quantitative studies were conducted. We choose to make two studies in order to acquire a broad insight into the consumer's behaviour toward packaging size variation. The research was carried out in two phases. Initially, study 1 was conducted to investigate the influence of packaging size variation on purchase intention, independently of changes in unit price and to discover the preferred packaging size of olive oil for customers when the unit price of $100 \mathrm{ml}$ is the same for all the sizes.

Study 2 comes as a complement for study 1 which makes the results clearer through studying the effect of packaging size variation on purchase intention by accounting for the norm that a bigger package has smaller unit price. The most important advantage from doing two studies is to be able to better analyse and understand this social phenomenon on which we face in our everyday life and improve the validity of the research.

The experimentation carried out consisted in displaying different stimuli (Olive oil bottles) to a sample composed of US participants. US market was chosen because olive oil has gained the interest of consumers, and Tunisia is ranked 6 out of 14 in implementation worldwide by US consumers [3]. In addition to that, US represent the second export destination of Tunisian olive oil in bulk. Therefore, it represents an opportunity for Tunisian producers of branded olive oil to attract and satisfy more customers.

University and Sfax University aiming to promote the Tunisian Olive oil and encouraging exports of branded olive oil. 


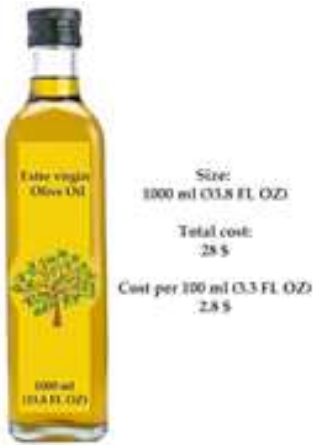

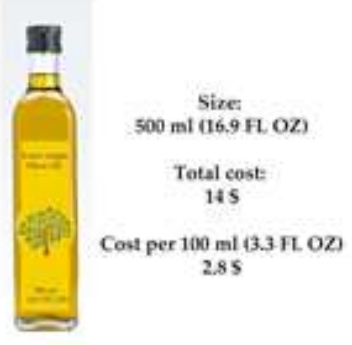

Figure 2. Stimuli used for study 1.

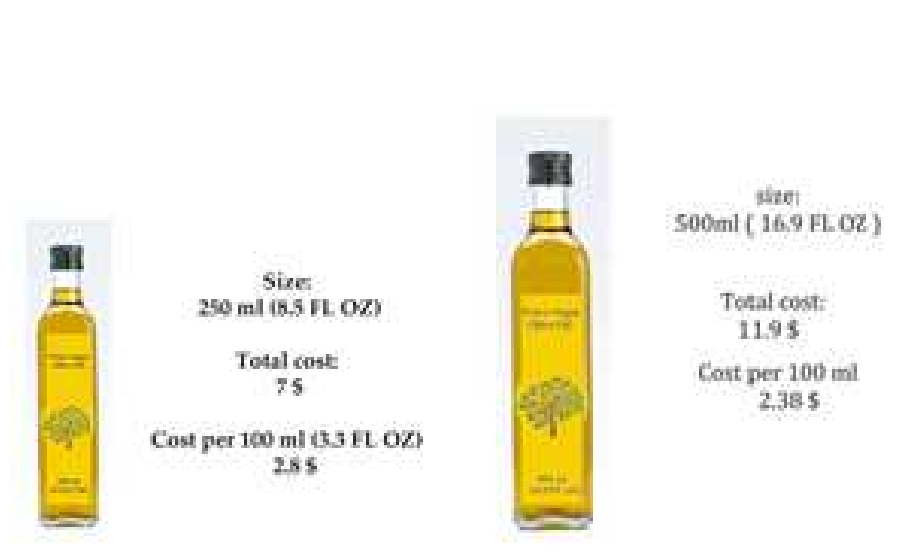

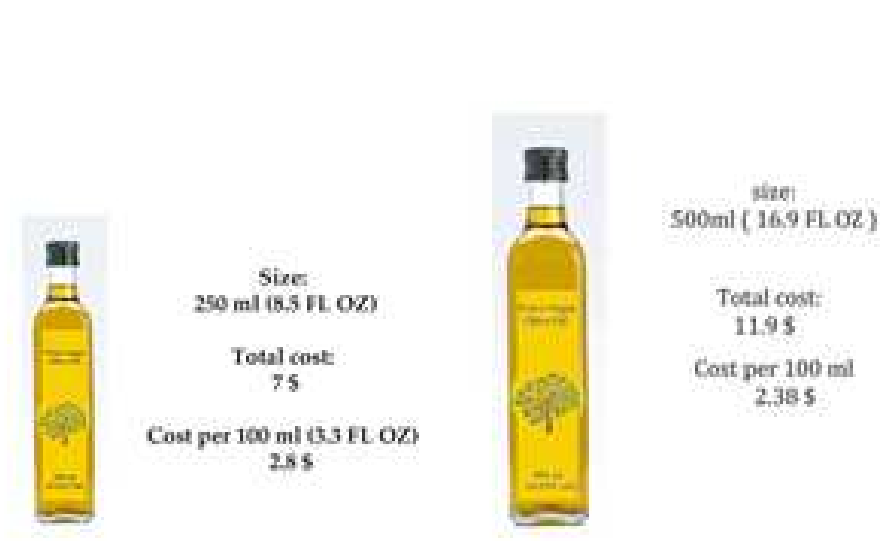

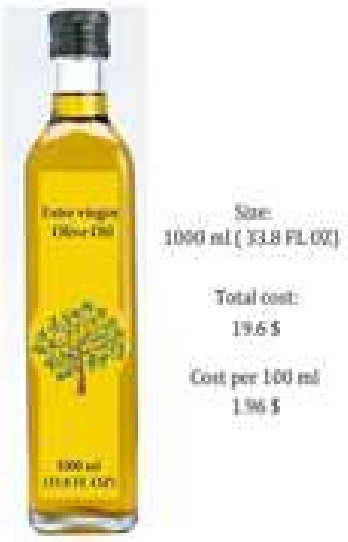

Figure 3. Stimuli used for study 2.

During the experimentation, each participant was exposed to only one stimulus, then answering the questionnaire. At the end of the questionnaire the participant is exposed to all stimuli in order to answer the choice question, knowing that he can't retreat to the preceding questions. The data were collected online using Qualtrics which is a subscription software.

\section{Results}

In order to test whether packaging size has an effect upon perceived value for money and purchase intentions, one way ANOVA was used.

\subsection{Study 1}

The first study aims at understanding whether packaging size variation affects or not purchase intention and if it is mediated by value for money when the unit price per $100 \mathrm{ml}$ is the same for the total sample of $\mathrm{N}=288$ participants.

Table 1. Anova Results - Study 1.

\begin{tabular}{lll}
\hline & F & Signification \\
\hline Quality & 0.155 & 0.856 \\
Value for Money & 8.085 & 0.000 \\
Price & 18.026 & 0.000 \\
Purchase intention & 8.350 & 0.000 \\
\hline
\end{tabular}

\subsection{Study 2}

Our second study aims to understand whether packaging size variation affects or not purchase intention and if it is mediated by value for money when the unit price per $100 \mathrm{ml}$ varies from size to size for the total sample of $\mathrm{N}=275$ participants.

Table 2. Anova Results - Study 2.

\begin{tabular}{lll}
\hline & F & Signification \\
\hline Quality & 0.098 & 0.907 \\
Value for Money & 6.814 & 0.001 \\
Price & 10.812 & 0.000 \\
Purchase intention & 8.747 & 0.000 \\
\hline
\end{tabular}

In USA, for study 1 , the three bottles sizes were evaluated by a sample of 288 US participants and were evaluated by sample of 275 US participants for study 2. Outcomes from these two studies show similar results according to the perception of the product quality. Consumers perceive the same quality for the three different bottle sizes and from the two cases of price. Regarding value for money and price, results are different. According to value for money, we noticed for study 1 that the difference between the three groups is significant $(\mathrm{F}=8.085 ; \mathrm{p}<0.05)$. Second, in the case of this study when the unit price for the three bottles is the same, US consumers consider the little size as the one which gives them better value for money then the medium size, and the medium size gives better value for money then the big size. Finally, 
according to the price, the difference is also significant $(\mathrm{F}=18.026 ; \mathrm{p}<0.05)$ and the little size is considered as the less expensive while the big one as the more expensive, which is very logic.

Now, according to the second study, when unit price is not the same and it changes according to the general low of little price for the bigger size, first of all, according to value for money the difference is significant $(\mathrm{F}=6.814$ : $\mathrm{p}<0.05)$ and US consumers, in this case get the best value for money from the medium size. Second, the difference between the three groups in price perception is also significant $(\mathrm{F}=10.812$; $\mathrm{p}<0.05)$ and the consumers keep their same attitude for the price when the unit price is the same and when it changes, they keep consider the large size as the most expensive and the little one as the cheaper.

In general, the results show that packaging size variation doesn't affect quality perception but affects value for money and purchase intention, and that consumers prefer the smallest sizes of olive oil bottles because it fits with their needs in olive oil and it gives better value for money than other sizes.

The mediation analysis is conducted with the three sizes of olive oil bottles with the purpose to investigate the hypothesis that value for money $(\mathrm{M})$ mediates the effect of packaging size (X) on purchase intention (Y).

In our study we have only one variable that is expected to mediate the relationship, for this reason we used Hayes' simple mediation model "Model 4" to conduct the analysis (Hayes 2013).

The overall mediation results show that there is a total mediation (see: Figure 4: Research Model with Mediation analysis Results (Study 1)) between Size and purchase intention through value for money when the unit price of olive oil is the same for all the sizes. This implies that the size of olive oil bottle doesn't affect directly the purchase intention, otherwise the consumer based his reasoning on value for money, he choose the size which offers the best value for money, then he decides to buy that size of olive oil bottle. Indeed, when unit price is lower, the mediation is partial, consumer can base his purchase intention on the better value for money but the size also can directly affect purchase intention, the two paths are significant (see: Figure 5: Research Model with Mediation analysis Results (Study 2)) but the effect of packaging size on purchase intention was more expressive with the presence of the value for money.

\section{Discussion}

Should an exporter adapt the packaging size of his products to the needs of the target markets? Does this tool (size) of the packaging affect purchase intention? Finally, does value for money has an impact on this relation between packaging size and purchase intention? These are the questions having constituted the driving force of the current study. Our results show is a significant effect of the packaging size on value for money and purchase intention, but not significant on perceived quality.

In fact, on the basis of this finding, there has been found support for hypothesis 1 (H1) which postulates that packaging size can influence customers' purchase intentions. This result confirms previous studies suggesting that the choice of the packaging size is crucial for decision-making [12].

Nonetheless, it is of great interest to see how the three bottles with three different sizes in addition of price control through two studies affect purchase intention.

First of all, in the case of the same unit price for the three packaging size, consumers prefer buying the little size $(250 \mathrm{ml})$ which was evident and consistent with previous researches where consumers prefer using smaller packages because they use them more sparingly. Second, in the general case, results become different, and consumers in this case, prefer buying the medium size, this transition could be possible explained by the reasoning of earning money, getting more quantity and keep the size relatively small.

Regarding to the mediation, the findings of the current paper support the proposed mediation relationship: Packaging size - Value for money - purchase intentions, indicating that the packaging size is linked to value for money, and in turn value for money is significantly and positively linked to purchase intentions. This finding was evident for our two studies. However, the direct effect of Packaging size on purchase intention was significant only in study 2 when the price changes along with the size.

Finally, the effect of packaging size variation on the quality perception was not significant. For US consumers, the size is a parameter of the packaging, which does not affect quality perception. For them, the content, the brand, the shape, country of origin, labels are the same whatever is the size. Therefore, they consider the size as a parameter related to consumption more than a parameter giving information about the product and its quality.

\section{Conclusion}

The paper at hand has provided international marketers and marketing managers with various considerably important findings. This section aims to present specific managerial implications and concludes with limitations that provide ideas for further research.

\subsection{Managerial Implications}

In response to today's needs and changes in the international market in which many products travel all around the world, this study investigates the impact of packaging size upon perceived value for money and purchase intentions. Although existing literature has provided ample evidence that packaging size is able to influence consumer's behaviour and decisions-making, still scarce research has explored what the size should be to succeed in exporting to new markets and won more consumers. Therefore, it can possibly enhance perceptions value for money and lead to higher purchase intentions; the current study revealed that smaller packs are the optimal solution.

First, the present study indicated that customers make judgments in terms of what they pay and what they will get. 
From a managerial lens, this should not be overlooked from marketing practitioners who desire to yield perceptions of originality and genuineness through their market offerings. Especially for foreign local products which do not carry the name of a prominent global brand, it deemed critical marketing managers to outline these cues that will make the product able to be placed in the customers' basket.

The current paper extends the discussion around packaging size, revealing that consumers associate the size with the value for money and this effect can lead to higher purchase intentions. In detail, the current research provided evidence indicating that the exclusive of packaging size adaption to the new markets will make the value for money of this product very less, consequently will lead to a big failure.

\subsection{Limits of the Study and Future Research}

The current research considers only one product category, olive oil. This product category refers to traditional products, which are strongly connected to the country of origin. Further research could include replication of this study with another product category. Moreover, the research was held in the US markets and results may not be directly applicable to other markets. A cross-cultural study could be conducted in other Mediterranean countries with the specific product category, such as Greece, Spain and Italy considered as big Olive Oil producers and consumers.

To make the research results more relevant for managers, this research should be conducted in a point of sale environment to stimulate a real purchase decision in front of retail shelf of olive oil bottles with different sizes.

Finally, future studies can consider the shape of the container as a covariate variable, which can affect perception of the packaging size.

\section{Appendix}

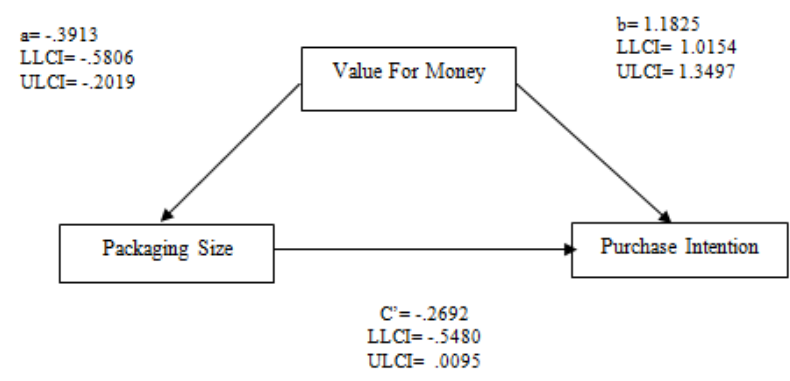

Figure 4. Research Model with Mediation analysis Results (Study 1).

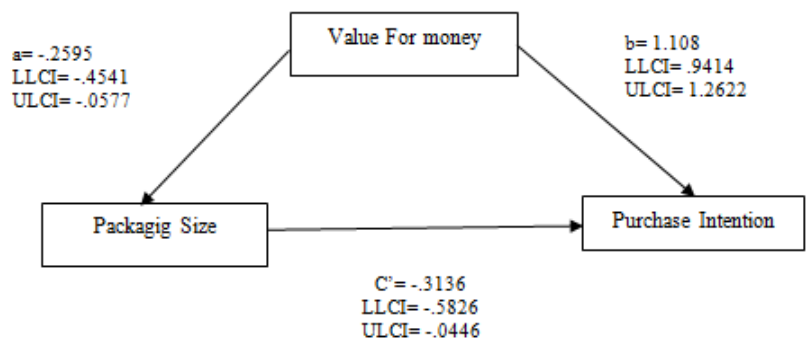

Figure 5. Research Model with Mediation analysis Results (Study 2).

\section{References}

[1] Ammar, O. Garbout, S. \& Trabelsi Trigui, I. (2018). Co-design and chronic regulatory focus: a cross-cultural study and suggestions for future e-marketing practices. 3rd Conference of ICDEc, 3-5 May, Brest, France.

[2] Ammar O., Trabelsi Trigui, I., (2017), "Consumer engagement in packaging co-design: A research model proposal", CMC Conference 2-4 Mai, Saragosse, Espagne.

[3] Delgado, C., Gómez-Rico, A., \& Guinard, J. X. (2013). Evaluating bottles and labels versus tasting the oils blind: Effects of packaging and labeling on consumer preferences, purchase intentions and expectations for extra virgin olive oil. Food research international, 54 (2), 2112-2121.

[4] Field, A. (2009). Discovering statistics using SPSS. Sage publications.

[5] Gómez, M., Martín-Consuegra, D. \& Molina, A. (2015). The importance of packaging in purchase and usage behaviour. International Journal of Consumer Studies, 39 (3), 203-211.

[6] Hayes, A. F. (2017). Introduction to mediation, moderation, and conditional process analysis: A regression-based approach. Guilford Publications.

[7] Imram, N. (1999). The role of visual cues in consumer perception and acceptance of a food product. Nutrition \& Food Science, 99 (5), 224-230.

[8] Karoui, M. et Trabelsi Trigui, I. (2019). Smart packaging: Consumer's perception and diagnostic of traceability information, 4th Conference of ICDEc, 3-5 May, Beirout, Lebanon.

[9] Kupiec, B., \& Revell, B. (2001). Measuring consumer quality judgements. British food journal, 103 (1), 7-22.

[10] Martinez, M. G., Aragonés, Z., \& Poole, N. (2002). A repositioning strategy for olive oil in the UK market. Agribusiness, 18 (2), 163-180.

[11] Prendergast, G., \& Pitt, L. (1996). Packaging, marketing, logistics and the environment: are there trade-offs? International Journal of Physical Distribution \& Logistics Management, 26 (6), 60-72.

[12] Raheem, A. R., Vishnu, P. A. R. M. A. R., \& Ahmed, A. M. (2014). Impact of product packaging on consumer's buying behavior. European journal of scientific research, 122 (2), 125-134.

[13] Rettie, R., \& Brewer, C. (2000). The verbal and visual components of package design. Journal of product \& brand management, 9 (1), 56-70.

[14] Rundh, B. (2009). Packaging design: creating competitive advantage with product packaging. British Food Journal, 111 (9), 988-1002.

[15] Schnurr, B. (2019), Too Cute to Be Healthy: How Cute Packaging Designs Affect Judgments of Product Tastiness and Healthiness, Journal of the Association for Consumer Research, July.

[16] Silayoi, P., \& Speece, M. (2004). Packaging and purchase decisions: An exploratory study on the impact of involvement level and time pressure. British food journal, 106 (8), 607-628.

[17] Zeithaml, V. A. (1988). Consumer perceptions of price, quality, and value: a means-end model and synthesis of evidence. The Journal of marketing, 2-22. 